\title{
Mixed Accents: Scottish Children with English Parents
}

\author{
Sarah Thomas and James M Scobbie \\ Clinical Audiology, Speech and Language Research Centre \\ Queen Margaret University, Edinburgh, United Kingdom
}

\begin{abstract}
Abrist
We discuss accent mixture and the creation of idiosyncratic phonological systems in acquisition, with a focus on Scottish English. Such mixing is in addition to the relatively stable sociolinguistic systems of variation expected within a speech community, and arises when parents have radically different accents from each other or from the child's peers or other adult models. In terms of traditional geographic dialectology, there are a number of isoglosses around the Scotland/England border, but modern social mobility means that in some Scottish cities there are large numbers of families with at least one non-Scottish adult accent acting as a model for acquisition, which may feed into phonological change. Of particular interest is the influence of Southern British English accents.
\end{abstract}

We exemplify the issues with two short case studies. The first concerns a child with mixed Scottish/English input in the home. His speech patterns do indeed indicate the acquisition of a mixed system. The second focuses on inter-sibling variation, looking at two sibling pairs who exemplify a different mix of accent features from each other. We examine two main diagnostics: monophthongal vs. diphthongal productions of the vowels in FACE and GOAT; and rhoticity. We also describe a parental demographic and accent attitude questionnaire as part of Case Study 2. The results support the need for speaker-by-speaker study of how incompatibility between two target systems is handled. We conclude that descriptions of mixed accents should be more common in the literature and approached on a feature-by-feature basis to help develop models of accent interference.

Keywords: acquisition, dialect mixing, sociophonetics, variation, phonemic inventory.

\section{Introductiop}

\subsection{Mixed accents of English}

The majority of research on English child language acquisition focuses on monolingual children, and the vast majority of that on contexts where a single standard variety is being acquired. Even when approached from a sociolinguistic perspective, the general issue of how monolingual children acquire a language when faced with input in more than one geographically distinct native accent receives suprisingly little attention, whether the situation arises due to geographical relocation of the child during acquisition (Chambers 1992; Taliamonte and Molfenter 2007) or childhood in a 
single location (Kerswill 1996; Kerswill and Williams, 2000; Scobbie 2005, 2006; Surek-Clark, 2000). The lack of literature on such cases is surprising: such families are relatively common in modern speech communities. The study of how social or gender variation within a single speech community is acquired is also surprisingly uncommon (but see for example Roberts and Labov 1995 or Docherty et al. 2002, 2006). The predominantly monodialectal literature in acquisition studies, moreover, tends to focus on standard varieties of English, in particular Southern Standard British English (SSBE) - also known traditionally as Received Pronunciation (RP) - and General American (GA). However, many other significant varieties of English do not have such as clear status as national and indeed international standards. Without such status such varieties tend to lack the sort of accepted codification typically required by applied linguists as a foundation, whether they are building resources in language learning, language teaching, speech technology, or in our particular are of interest, clinical and development assessments of typical phonological acquisition.

For example, English has been spoken Scotland for centuries, and has a long-standing history of development and interaction. Scottish English has to be seen in the context of English spoken in England; in the context of varieties of its sister language Scots; and independently in its own right (Johnston 1999, 2007; Corbett and Stuart-Smith 2012, 2013). Today, Scottish English comprises a number of regional and social varieties with distinctive lexical, phonological and phonetic features: but clear and widely-accepted descriptive norms for a standard variety of Scottish English are scarce, as are definitions in the literature of such a standard variety (but see e.g. Giegerich, 1992 for an account of the phonological system). This may be in part because Scotland has not been an independent nation state like Canada, Australia, NewZealand etc., for around 300 years, while being politically, socially and geographically part of the UK. Similar issues arise, however, for other Englishspeaking nations and regions, becauseSSBE or GA are the object of enquiry for the bulk of literature on English linguistics. In the Scottish context, Scobbie et al. (2007) reviewed the relevant work on acquisitional phonological norms in an attempt to provide a comprehensive overview of information on Scottish English.

While it is possible to describe acquisitional norms for speakers of the same accent, such normoriented literature tends to avoid complexity due to bilingualism, sociolinguistic variation and idiosyncratic mixed accents. Taking a simple, variation-free approach is, indeed, problematic for accents in which there is no a clearly defined and accepted standard variety to act as a "neutral" reference point. In ourview, avoiding such complexities is also theoretically undesirable, even when the context relates to SSBE or GA. It is important to address the growing number of families comprising speakers with combinations of accents, or where children are being brought up in a dialect area markedly different to that of their parents. Thanks to an increasingly mobile population, many native speakers of English are exposed to multiple, incompatible varieties as input during acquisition: that is, varieties with differences in phonological inventory, in phonetic realisation, and in lexical incidence. For example, English-accented speakers who have moved to Scotland may bring up children who acquire mixed or intermediate accents, reflecting aspects of phonologically and phonetically incompatible inputs from within and outwith the home. We have previously explored such situations in the Shetland Isles (Scobbie 2005, 2006) and in Edinburgh (Hewlett et al., 1999), while Thomas's unpublished research in Glasgow (writing as Watson, 2009), forms the basis of Case Study 1 , below. 
Traditionally, research into variation in Scottish accents has been underpinned by the assumption that speakers locate on a continuum from vernacular Scots to Scottish Standard English (least to most formal), along which they style-switch or style-drift according to their conversational circumstances (Stuart-Smith 1999). But non-Scottish accents do not feature on this continuum, however, nor is it clear what range of possibilities exists for composite or variable systems, given the large number of differences between these broad classes of accent, and such issues remain to be explored.

Recent research into Scottish/English accent interference has however revealed a great deal about identity and dialect use, in particular by looking at populations along the Scottish-English national border (AISEB 2012). This research has identified which features are perceived as markedly Scottish or English by interlocutors, whether the use of these features is socially stratified, and what sound changes may be taking place, using both acoustic analysis and qualitative interviews with native speakers. However, given the increase in speakers of English dialects moving to diverse locations throughout Scotland (Scottish Government, 2011), these factors need to be investigated far from the border, such as in Scotland's densely populated Central Belt (e.g. Braber and Butterfint 2008; StuartSmith et al. 2013). Given that children are active members of their speech communities (Smith et al. 2007), that they acquire systems forged from the models around them, and that they participate in sound changes within these communities (Roberts and Labov 1995), looking at Scottish children of English parents throughout Scotland - and not only along the Scottish-English border - enables a range of theoretical questions relating to acquisition and bidialectalism to be addressed.

Dialect variation within Scotland al so has to be taken into account when considering the interplay of Scottish vs. non-Scottish elements in a speaker's accent. There are marked social and geographical differences between varieties of English (Wells 1982; Corbett and Stuart-Smith 2013), and also between Scottish English and Scots (Johnson 2007). Therefore what occurs when SSBE is mixed with Scottish-accented Standard English can be expected to vary depending on context. This issue is particularly germane in terms of Scotland's two largest cities, Glasgow and Edinburgh, not least given their different socioeconomic compositions and prevalence of SSBE features in the parental accent.

\subsection{Context and current situation - the Scottish Continuum}

Much work on language varieties in Scotland is based on the presumption that Scottish speakers have available to them a continuum of varieties branching from Scots at one end - traditionally assumed to be more working-class - to Scottish-accented Standard English (SSE) at the other. This means SSE can be compared to SSBE and be classed as a standard variety, to set against vernacular competitors. There are many examples of research into Scottish English which are predicated on this assumption (Aitken 1979; Wells 1982; Macafee 1997; Chirrey 1999; Braber and Butterfint 2008; Corbett and Stuart-Smith 2012, 2013; Schützler, in press). Stuart-Smith (1999) states that speakers of Scottish English, particularly in the Central Belt, have a tendency to style-drift, that is, to move up and down the continuum as required by their current circumstances.

It is hard to be sure, however, that a continuum based on two inherently Scottish phonological systems (Scots and SSE) can be extended to SSBE, nor whether a continuum is the appropriate way to approach the influence of SSBE might have on families and communities. Young children can be 
vehicles for linguistic change (Smith et al., 2007), but there is no consistent and clear role for a continuum when we consider how children who are growing up in multi-accent environments settle on their own system. One clear example that has attraced some attention arises in multilingual or multi-ethnic contexts. In their study of Glasgow-Pakistani high school girls, for example, Alam and Stuart-Smith note that "ethnicity is integrally linked with locally-salient identity" $(2011,216)$. Their results demonstrate not only perceptual indicators of membership of the Glasgow Asian community, but moreover that the variants within that community are the socially stratified, indicating membership of the more conservative or the more modern groups of students. Perhaps the influence of parental English accents such as SSBE on children growing up in Scotland could be approached in exactly the same way (as being expressive of membership of a community), even though SSBE itself has a very different status when viewed in the wider context of the UK.

Scotland's population is currently at its highest ever level, with $5.3 \mathrm{~m}$ inhabitants according to Scotland's Census 2011 (Scottish Government ,2011). Glasgow is the largest city in Scotland, with a current population of 593,000 in the Glasgow City Council area alone. From a sociolinguistic point of view, "Glasgow as a city, and Glaswegian as a linguistic variety, have both long been heavily stigmatised." (Braber \& Butterfint 2008, 24). It has also been noted that some speakers of the Glaswegian dialect perceive it as having covert prestige, with Glaswegian identity and solidarity, particularly among working-class speakers, signalled through its use (Stuart-Smith 1999; StuartSmith et al. 2007). As far as other accents are concerned, British English accents traditionally regarded as prestigious, particularly those similar to RP, for example, do not have the same level of status as they do elsewhere; indeed, in some areas of Glasgow they are "regarded with hostility" (Stuart-Smith 1999, 204).

Edinburgh is smaller than Glasgow, with a current population of 477,000 . It has been historically seen in a more positive light than Glasgow, bringing to mind "culture, tourism, Scottish heritage, and shopping" as opposed to Glasgow's "Gorbals, tenement slums, violence and industrial corrosion" (Maver 2000, 281). Its socioeconomic make-up remains markedly different from that of Glasgow; only $15 \%$ of the most deprived areas in Scotland are located in the City of Edinburgh, as opposed to Glasgow, which contains 30\% of these areas (Scottish Government, 2012).

Such demographic disparities between Glasgow and Edinburgh lead us to expect ".... a greater influence of Anglo English on the Edinburgh middle class..." (Scobbie et al. 1999: 242) than in Glasgow. This view is based on the assumption that if parents have England as country of birth, identify as English, and have a higher social class, then this implies a greater likelihood of SSBE being spoken by parents, and the 1991 census has shown Edinburgh had more middle class residents, and more English residents than Glasgow. This trend continued in 2001 (Scobbie et al. 2007), and in the 2011 census (Scottish Government, 2011) we can see that these patterns continue. Overall in Scotland 9\% of the population had been born in England and 83\% in Scotland, and a continuing imbalance in their distribution between the cities. When it comes to identity, in $201162 \%$ of Scots claimed to feel Scottish only, $18 \%$ both Scottish and British, and $2 \%$ to feel Scottish in combination with some other identity (i.e. over $80 \%$ have a Scottish identity). In comparison, just $8 \%$ felt they had a British national identity only, and 2\% felt English only. (For comparison, 1.4\% do not speak English well or at all, compared to the $30 \%$ of the population who claim to speak Scots.) Turning to the cities under discussion, in Edinburgh City council region, 49\% expressed a Scottish-only identity, 18\% 
Scottish and British and 18\% some kind of British identity (including specifically English) which is nonScottish. In Glasgow City council region, the comparable figures are $62 \%, 16 \%$ and $11 \%$. Finally, the difference in voting patterns in the independence referendum of 2014 were, unspurprisingly, very different in the two cities, with some areas of Glasgow voting for a politically independent Scotland, and Edinburgh voting strongly against, in favour of the UK status quo.

Roberts and Labov (1995) and Jacewicz et al. (2011) have demonstrated that younger children are able to utilise the same speech patterns as adults in their dialect area, so it can be hypothesised that children being raised in Scotland by Scottish-accented parents are likely to be successfully acquiring the dialect of their local area. It is further conjectured that children being raised in Scotland with English-accented parents are likely to have an increased incidence of English dialect features in their speech. Extensive work in Milton Keynes (in the south of England) by Kerswill (2003, Kerswill and Williams 2000) records various instances of regional dialect levelling, that is, the phenomenon whereby newcomers to the area affect the speech patterns of their children, and these changes in turn are spread to the wider population, leading to a "reduction in differences between dialects" (Kerswill, 2003: 5).

Based on the demographic information given regarding Glasgow and Edinburgh, and attitudes to different varieties in the former, it is also possible that children being raised in Glasgow with English accented parents may not have as high an incidence of English dialect features as those in Edinburgh. The pejorative view of English dialects in parts of Glasgow and the fact that use of the Glaswegian dialect can be seen as a sign of solidarity could lead to a reduction in the use of those features. We would expect, in a full sociophonetic study, for the balance of dialect interference to differ between the cities, reflective of their own historical character and contemporary patterns of migration.

\subsection{Phonological vowel systems of Scottish-accented Standard English and Standard Southern British English}

The traditional analysis of the vowel system of Scottish-accented Standard English (SSE) contains 13 vowel phonemes, with 10 monophthongs (including schwa) and three diphthongs (Scobbie et al. 2007). One of the most readily identifiable markers of a Scottish accent is rhoticity (use of postvocalic/r/). There is, however a reduction in the use of this feature by some Scottish speakers, particularly males in working-class areas of Glasgow (Stuart-Smith 2007; Lawson et al. 2011; StuartSmith et al. 2014).

Table 1 below is based on the widely-used Standard Lexical Sets for English introduced by John Wells (1982). He defined each lexical set on the basis of historical factors relevant to the lexical incidence of phonemes in many accents of English, but not quite in enough subtlety for Scottish English, given the strong influence of Scots, so the sets need to be slightly augmented to deal with aspects of SSE and Scots beyond the topics under discussion in this paper (Johnstone 1997). Table 1 contains reference transcriptions for Scottish Standard English based on Wells (1982), subsequently amended and updated by Matthews (2001), Scobbie et al. (1999) and Scobbie et al. (2007) to reflect phonetic vowel qualities in common use, plus the effect of increasingly rhotic middle-class varieties (Scobbie et al. 2012; Lawson, et al. 2013). See Schützler (in press) as well as Johnston (1997) for alternative proposals and further discussion. 
In Table 1, we present a middle class/non-vernacular version of the phonological system of SSE, though the phonemic patterns are largely still valid for more phonetically vernacular versions. The monophthongal nature of FACE and GOAT are reflected in the phoneme labels /e/ and /o/, though GOAT is in fact phonetically higher than cardinal [o]. LOT and THOUGHT are lower, featuring the same vowel / $/$ /. FOOT and GOOSE are assigned the label / $\mathrm{t} /$, but the vowel is often only mid-close phonetically (Scobbie et al. 2012). The third column demonstrates a typical modern rhotic pattern, including a heavily rhoticised vowel in NURSE typical of more middle class speakers (Lawson et al. 2013). Note the phonetic quality of START is [a], an exclusively pre-rhotic allophone of /a/, and that $/ \mathrm{r} /$ symbolises a bunched post-alveolar approximant. PRICE varies due to the Scottish Vowel Length Rule (Scobbie et al. 1999). For details of the phonetics and potential phonological changes happening in more vernacular accents, especially the potential phonological repercussions of derhoticisation, see the words cited.

Table 1: Scottish-accented Standard English (SSE) lexical sets with phoneme labels

\begin{tabular}{|c|c|c|c|c|c|}
\hline$\overline{\mathrm{KIT}}$ & I & FLEECE & $\mathrm{i}$ & NEAR & ir \\
\hline DRESS & $\varepsilon$ & FACE & e & SQUARE & er \\
\hline TRAP & $\mathrm{a}$ & PALM & $\mathrm{a}$ & START & ar \\
\hline LOT & 0 & THOUGHT & 0 & NORTH & or \\
\hline STRUT & $\Lambda$ & GOAT & O & FORCE & or \\
\hline FOOT & t & GOOSE & \# & CURE & (j) $\mathrm{tr}$ \\
\hline BATH & $\mathrm{a}$ & PRICE & $\mathrm{ae} \sim \partial \mathrm{i}$ & NURSE & $\gamma^{\prime}$ \\
\hline CLOTH & 0 & CHOICE & oi & happY & e \\
\hline commA & $\Lambda \sim \partial$ & MOUTH & ot & lettER & $\gamma$ \\
\hline
\end{tabular}

Schützler (2010; in press) draws particular attention to the use of monophthongs for FACE and GOAT as an aspect of variation in SSE. It is known that diphthongs can somestime be found in FACE and GOAT in SSE (Aitken 1979), and one reason may be that diphthongal vowels for FACE and GOAT are the norm in SSBE, and that some Scottish speakers subconsciously aiming for a standard variety adopt elements of SSBE into SSE as they drift on the continuum (Aitken 1979). It is not clear, however, the extent to which this is an optional and dynamic use of diphthongisation as phonetic style-shifting or accommodation by speakers wishing to project particular social meaning (e.g. British rather than Scottish identity). It might instead be a relatively stable outcome of mixed accent input to a child's acquisition process in those suburbs, nurseries and schools with (sufficiently large numbers of) SSBE speaking families mixed with SSE-speaking families. The only point on which there is general agreement is that a monophthongal vowel in FACE or GOAT is an "important identity marker" (Schützler 2010, 159) for Scottishness.

Rhoticity is also a crucial aspect of SSE. Although there are some rhotic areas of England, such as Lancashire in the north (Beal 2010), the majority of dialects spoken in England nowadays are nonrhotic. These non-rhotic dialects have tended to display a larger vowel inventory (Table 2 ) due to the 
greater use of diphthongs, following historically from vocalisation of $/ r /$ as an aspect of nonrhoticity; for example, in SSBE there are around 20 vowels, typically five long monophthongs, seven short monophthongs, and eight diphthongs (Wells 1982; Roach 2004; Howard 2007).

Table 2: Southern Standard British English (SSBE) lexical sets with traditional phoneme labels

\begin{tabular}{|l|l|l|l|l|l|}
\hline KIT & I & FLEECE & i: & NEAR & Iə \\
\hline DRESS & $\varepsilon$ & FACE & eI & SQUARE & eə $\sim \varepsilon:$ \\
\hline TRAP & a & PALM & a: & START & a: \\
\hline LOT & p & THOUGHT & o: & NORTH & o: \\
\hline STRUT & $\Lambda$ & GOAT & oU & FORCE & o: \\
\hline FOOT & U & GOOSE & u: & CURE & Uə $\sim$ : \\
\hline BATH & a: & PRICE & aI & NURSE & $3:$ \\
\hline CLOTH & p & CHOICE & oI & happY & i \\
\hline COmmA & D & MOUTH & aU & lettER & ə \\
\hline
\end{tabular}

\subsection{Variation and change: the role of attitudes to varieties of English in Scotland}

Bringing these issues together, we can see why children and adolescents are vehicles for linguistic change, and not merely parts of a synchronic system of low level sociophonetic variation (Kerswill 1996; Smith et al. 2007). Roberts and Labov are clear that even "young children are indeed members of the speech community, and no description of these communities is complete without their inclusion" $(1995,101)$. The output of acquisition is not simply a parent-identical phonology, even in cases when the parents' accents are in fact phonologically identical. Instead, the child integrates a range of influences: mixed parental and caregiver input (Roberts and Labov 1995; Kerswill and Williams 2000; Matthews 2001; Gordeeva 2005); peer or sibling influence (Starks and Bayard 2002); dialect mixing across borders (AISEB 2012); a mismatch between parental accent and the community (Chambers 1992; Scobbie 2005, 2006; Tagliamonte and Molfenter 2007); and even the use of nonlocal accents on television (Stuart-Smith et al. 2007, 2013). All of these factors are, moreover, inextricably linked with the attitudes of child and adult speakers to both their own and others' use of regional varieties because "speakers' phonetic variation can affect how others socially evaluate them" (MacFarlane and Stuart-Smith 2012, 764).

Scotland is a complex linguistic environment and English/Scottish aspects of accent have been used as indicators of both local identity and socioeconomic status (Macaulay 1975, 1976; Macafee 1997; Preston 2002; Smith et al. 2007; Stuart-Smith 2007; Braber and Butterfint 2008; MacFarlane and Stuart-Smith 2012). Such clarity of social meaning begins to break down when populations moveand mix: children born in Scotland can acquire accents which have characteristics of both SSE and SSBE, and while such children are regarded as idiosyncratic outliers whose systems are of little systematic phonological interest, ourview is that such mixtures are intrinsically interesting from phonological and acquisitional perspectives as well as from the perspective of sociophonetics.

The broad phonological differences between SSE and SSBE vowel systems suggest that numerous phonological reflexes of accent mixture might be found, even in children whose social and family 
backgrounds tend to lead to the acquisition of the same standard variety. In the future, the accents of Standard English in Scotland might become even more variable, such that the concept of a linear continuum with SSE at the most standard end is untenable. Or it might be that a single standard Scottish accent arises as a nexus, distinct from both SSBE and vernacular and more strongly Scotsinfluenced varieties. From sociolinguistic and acquisitional points of view, this is a particularly interesting situation, which will be played out across the whole socio-geographical spectrum in Scotland, in time. But even from a purely structural, phonological point of view, just the issue of what current SSE features might change in middle class standard speech given the influence of SSBE is an interesting one. We might expect, for example, that rhoticity would be an important feature to retain, given its pervasive phonological role differentiating SSE and SSBE, and for differentiating middle class from vernacular Scottish English (Stuart-Smith 2007; Stuart-Smith et al. 2014). Diphthongisation of FACE and GOAT (Aitken 1979; Schützler 2010) is also an important area to consider.

We turn now to two pilot case studies which focus, like Hewlett et al. (1999), on Scottish-born and resident children who have an English parent or parents. These independent case studies each reflect in their own way some effects of mixed accent input and the potential for individual variation which and confirms avenues that can be quantified in a full survey.

\section{Case Studies}

\subsection{Case Study 1: Glasgow boy}

Aim

This study is based on unpublished work by the first author (writing as Watson) in collaboration with Jane Stuart-Smith (Watson 2009). The goal was to investigate the possible effects of growing up with parents with potentially incompatible varieties of English on a young child's vowel development. The research question was: can the presence of different varieties of English have an influence on a child's vowel system? Given the discussion above, the hypothesis entertained was that the child's vowel system will show features of both accents.

\section{Participants}

A male child aged 3;1 (years; months) living in Glasgow, Scotland, with parents of differing Brit ish English accents. The parents were both university graduates. The father was from a middle class area of Glasgow, speaking Scottish Standard English (SSE), and the mother was from a town on England's south-east coast, using an accent that closely resembles Southern Standard British English (SSBE). The child attended a nursery school on Glasgow for two days per week, surrounded mainly by SSE peers and staff, and for the remaining three days of the working week he was in the care of his mother. At weekends and during evenings, the child was consistently exposed to the speech of both parents. This seems a pretty typical situation for children of this demographic. There is no reason to think that television viewing was out of the ordinary for this child, which means extensive exposure to SSBE and GA, with more limited exposure to SSE and other varieties of English (Stuart-Smith et al. 2013). 


\section{Method}

A series of six one-hour recording sessions were conducted over a period of three weeks. The first author went to the family home, and the child was asked to participate in various picture naming tasks (selected with the elicitation of particular lexical set features in mind) and to read rhyming books in three different circumstances: a) repeating words after his mother; $b$ ) repeating words after his father; and c) taking part in the tasks by himself. The recorded data was transcribed by the researcher using PRAAT (Boersma, 2001). Instances of words where the child made use of the FACE and GOAT lexical sets during the recording sessions were counted, and the most common usage was ascertained in this manner. Only clear tokens were analysed, so for the vowels discussed below, 95 tokens were discarded due to shouting, whispering, or masking, while 71 were analysable.

\section{Results and discussion}

The results indicated that the child appeared to be developing a mixed accent, therefore confirming the hypothesis. While the child varied in his speech for both vowels, as expected, his overall preferences in the FACE and GOAT lexical sets, often described as clear perceptual indicators of a Scottish accent in their monophthongal form, were mixed (Table 3).

Table 3-Case Study 1: Vowel variants within the family

\begin{tabular}{|c|c|c|c|}
\hline \multirow[t]{2}{*}{ Lexical set } & \multicolumn{2}{|c|}{ Parental use } & \multirow{2}{*}{$\begin{array}{l}\text { Child's most } \\
\text { common form }\end{array}$} \\
\hline & SSE (local) & SSBE & \\
\hline FACE $(n=36)$ & [e] & [eI] & [er] $(83 \%)$ \\
\hline GOAT $(n=10)$ & [o] & {$[\gamma v]$} & [o] $(60 \%)$ \\
\hline
\end{tabular}

The parents were consistent, as expected, in their usage. The child's speech patterns were highly varied. In the case of the FACE lexical set, of the 36 tokens that were suitable for analysis, the child used the SSBE variant [eI] on $83 \%$ of occasions, reflecting mainly the SSBE accent of his mother. In the case of GOAT lexical, the usage was more evenly mixed from a small sample, with the SSE variant [o] in a slight majority. The child produced examples of other lexical sets specified above in Table 1, and in general other parts of the system were more like SSE. Of note is that the child had occasional or partial merger of LOT and THOUGHT members, with 13/25 of the analysable tokens clearly indicating non-merger (i.e. like SSBE). The normal phonological interpretation of intermittent contrast is that the contrast exists, albeit perhaps always realised clearly (i.e. "once a phoneme, always a phoneme"). On such a view the child would be said to have an SSBE-like lack of merger.

This all clearly demonstrates that the child's mixed parental dialect input was having an impact on the acquisition of his vowel system; the varied use of a non-local feature elicited by picture naming tasks implies that the mixing of the two systems (which are incompatible in these features) can result in a measureable preference for one usage over another, but need not result in the exclusive use of just one variant. However, our interpretation is that this optionality seems to indicate variable or unclear phonology/phonologies rather than the creation of a new intermediate phonological system. 


\subsection{Case Study 2: Edinburgh siblings}

Aim

Case Study 1 addressed a single child. Since it might be expected that different individuals might show different patterns, even the same environment, a dataset collected for a different project (Ultrax 2013) was investigated to see whether siblings might display accent mixing. Siblings close in age and sharing a mixed-accent home environment are an interesting test case since the parental input, of whatever nature, ought to be relatively consistent. Of course, suble social variation (e.g. gender-specific patterns) is present in child directed speech (Docherty et al. 2002, 2006), but while in bilingual housholds a parent might use more than one language, in bidialectal or mixed accent homes, for a parent to switch from one accent to another appears peculiar and is often associated with metalinguistic mimicry. While Chambers (1992) and Tagliamonte and Molfenter (2007) looked at the variable effect on older and younger siblings when a whole family moves home to a new accent area, in our case study the context was static: the families all lived in the SSE-speaking Edinburgh area and the children were mostly brought up there from birth, with a few exceptional cases that don't affect the results below. The specific research question was whether siblings have similar mixed accent patterns.

\section{Participants}

We examined data from Group 1 of the ULTRAX project corpus, comprising 30 children. ULTRAX recruited a convenience sample of children of staff and students at Queen Margaret University and from a local school with a more mixed social demographic for a study using ultrasound tongue imaging. Of these, most had two Scottish parents and exhibited Scottish accents, and in the pool of participants there were 15 who were siblings, within six families. We focused on thes, in particular two of the sibling children who had a clearly mixed vowel system at an impressionistic level, conveying an influence of SSBE in addition to SSE. The other eleven siblings (from four other families) had consistently SSE accents at the level of observation, and so their phonologies are not reported further here. The nonsibling children had clear Scottish accents at a broad transcription level, even if they had mixed accented parents, so are not reported further. The two children identified as having an SSBE-influenced accent were both from families recruited from the university, with a generally middle class profile. In both families one parent was broadly SSE and one broadly SSBE.

\section{Method}

All the children had read word lists created for a different purpose containing a number of words which we can assess here for rhoticity and FACE diphthongisation. The diagnostic features were coded so that high values indicate an SSE-like system. The first was the Scottish monophthong in the FACE lexical set, which, given the small number of tokens, is included mainly for comparison with Case Study 1 . The second and more important diagnostic was rhoticity, i.e. the presence of a perceptible coda/r/ (cf. Table 1). Once the data were extracted and transcribed by the first author, it was checked and verified by the second author, an experienced transcriber.

Results and discussion 
First, it should be recalled that most of the sample of 30 were completely Scottish sounding, indicating no general influence of SSBE on these middle class children. This includes for example one SSE-speaking brother-sister pair whose mother's accent was self-reported to be "mixed" (see below) though she did clarify that it was mainly Edinburgh. In that family, the elder male sibling had lived in England till the age of four, but at a transcriptional level we detected no SSBE influence, so that family are not reported in more detail. (But we predict subtle effects of these mixed influences, e.g. in SVLR, as found in Hewlett et al. 1999.) Here, we focus on the two pairs of siblings for which one sibling had been picked out as clearly displaying some strong SSBE characteristics (unusually), i.e. characteristics which would be evident to family, friends and other new interlocutors. Moroever, at an impressionistic, holistic level, each of these children's sibling sounded consistently and clearly SSE. In otherwords, the two anglicised children had a different accent to their sibling despite being raised in the same mixed-accent family, in Scotland.

The impression of anglicisation can in part be explained by the different patterns found for the features quantified (Tables 4 and 5). The lower rhoticity values in tandem with associated vowel quality in particular seem to explain this impression of anglicisation, further underpinned by the apparently consistent use of a diphthongal vowel in FACE.

Table 4-Family A

\begin{tabular}{|l|l|l|}
\hline Sibling & Sibling A1 (male) & Sibling A2 (female) \\
\hline Age & $8 ; 7$ & $6 ; 8$ \\
\hline$\%$ monophthongal FACE & $0 \%(n=2)$ & $100 \%(n=2)$ \\
\hline$\%$ use of coda $/ r /$ & $14 \%(n=7)$ & $100 \%(n=7)$ \\
\hline
\end{tabular}

Table 5-Family B

\begin{tabular}{|l|l|l|}
\hline \multicolumn{1}{|c|}{ Sibling } & Sibling B1 (female) & Sibling B2 (male) \\
\hline Age & $12 ; 8$ & $10 ; 7$ \\
\hline$\%$ monophthongal FACE & $100 \%(n=3)$ & $0 \%(n=3)$ \\
\hline$\%$ use of coda $/ r /$ & $100 \%(n=9)$ & $67 \%(n=9)$ \\
\hline
\end{tabular}

Note that it is not the case that the boys had simply acquired SSBE: most other aspects of their system indicate a strong SSE influence, such as merged GOOSE and FOOT and merged LOT and THOUGHT; and rhoticity in B2 was in fact seen in only two thirds of the tokens observed. In each family one of the children was apparently making consistent use of only Scottish variants of both variables, whereas the other sibling demonstrated a majority of SSBE forms for some aspects of the 
phonology within a pattern of variation. Age and birth order varied; the only commonality was that the anglicised sibling was male.

Though this fits with the boy in Case Study 1, the consistent SSE accents of the brother-sister pairs plus extensive further casual observation of families in Edinburgh and Glasgow with SSBE-influenced girls lead us to conclude that the sex of the child is certainly not a universal factor. The hypothesis arising from these cases about variation within families is at this stage is theoretically weak, but clear: we can expect to see a wide range of behaviour. To be able to model such variation and even to be sure about the areas of the phonological system most affects, a larger sample is needed. If big enough, it might let us statistically model the likely influences on acquisition of such simple variables as sex and birth order, plus issues of external dialectal contact and individual personality, educational or childcare experiences and sociolinguistic factors. For purely phonological insights, it is unclear how big a sample might be required. Both diphthongisation of FACE and GOAT and rhoticity are however confirmed as suitable implicit variables which can be judged easily, and without the requirement for collecting explicit minimal pairs to check for homophony of GOOSE and FOOT or LOT and THOUGHT (both key Scottish features).

\section{Attitudinal questionnaire}

While we knew that these sibling pairs both had parents with different accents, we had litt le further information on their caregiving patterns, attitudes or identity comparable to Case Study 1 . We therefore attempted a small additional qualitative study with all the parents of the children involved in the ULTRAX study, and designed a questionnaire accordingly (Appendix 1).

As well as basic demographic information regarding the areas in which the parents and familiy had previously lived, and questions asking for an impression of their own and their children's accents, some attitudinal questions about their own, and their children's accents were included. Reference to slang was included to help the participants to distinguish phonology from issues of usage. More general attitudes to regional accents were also elicited, and participants were also given the chance to expand on their answers. A blank map of the United Kingdom was included to prompt the parent participants to draw their own linguistic isoglosses and write their opinions of the speech in the corresponding areas (Inoue 1996; Preston 2002).

Only four responses were obtained (R1-R4), and not, unfortunately, from either of the families in Case Study 2. However R1 was a mixed-accent family (father's accent was Northern English) whose child's system is clearly SSE, and R2 was the family mentioned above of SSE siblings whose elder son had been brought up in England for his first four years. The responses to the key attitudinal questions on linguistic change and usage and the importance of a standard accent appear in Table 6. Additional comments from the respondents, relevant to phonology, are paraphrased below.

Table 6-Parental responses to the attitudinal questions about slang

\begin{tabular}{|l|c|c|c|c|}
\hline Question & R1 & R2 & R3 \\
\hline $\begin{array}{l}\text { Do you think children speak with too } \\
\text { much slang? }\end{array}$ & No, I like slang & No & Yes \\
\hline $\begin{array}{l}\text { Do old people have more varied } \\
\text { accents than young ones? }\end{array}$ & $\begin{array}{c}\text { Yes, [older people are] } \\
\text { better spoken }\end{array}$ & No & Yes, more dialect/slang \\
\hline $\begin{array}{l}\text { Is it important to preserve local } \\
\text { accents and old-fashioned words? }\end{array}$ & Yes & Yes & $\begin{array}{c}\text { Use of old-fashioned words has a time } \\
\text { and a place }\end{array}$ & Yes \\
\hline
\end{tabular}




\begin{tabular}{|l|l|l|l|l|}
\hline It is important that we all speak with & No & No & & No \\
a standard accent to make \\
communication easy?
\end{tabular}

There are a mix of attitudes, but there was no strong call for a homogeneous standard dialect or accent in response to those specific questions, let alone an English one. Further spontaneous views were offered, however, containing somwhat negative attitudes to regional and Scottish accents.

R1, an East Coast Scot commented on her own accent that it is lazier/slower than West Coast Scottish. She also noted that North East Scotland sounds beautiful but "needs subtitles" for her to completely understand it. These mildly but overtly negative attitudes were emphasised with additional implicit criticism of Scottish accents, in that her child was judged by her as being better spoken because of his father's English accent, which was seen as "neutral". R1 did have positive views on Welsh ("lovely", "singing accent") and West-Coast Scottish ("singing up and down", as well as not being "lazy"). Her only additional view was that London English is a mixed variety. What we do not know is whether R1 is a speaker of Scots or a broad variety of Scottish English: she might have been referring to phonetic features below the level of phonol ogisation. All our questionnaire can tell us is the phonological background and her attitudes, to set against our impression of her child's Scottish accent. In R1's mixed accent family, the SSBE accent of a parent is seen as a positive influence on the child's system, though no phonological SSBE factors were identified by us in the speech of that child.

R2 responded to the question "Where do you think people start sounding different from your local area? What are the accents nearby that are different to your local area?" with the observation that the adjacent suburb contains more formally spoken people and more English accents, in comparison to her local area with its very mixed population, with some speaking quite formally and others using more slang and colloquialisms. This seems again to show an expectation that it is SSBE, not SSE, that will correlate with formality and wealth.

R3, who had noted young people use more slang and dialect than older speakers, was the only respondent to disapprove of slang, connecting greater wealth to better language use and better manners. She was also aware of social variation, commenting on noticeable changes in dialect between less affluent and more affluent areas. Since the demographics of Edinburgh show that English origin correlates with greater wealth and income (Scobbie et al. 1999), and since Scottishaccented friends are likely to be in the majority, this is an implicit critique of Scottish English.

R4's comments were less pejorative while still being socially observant, noting that people working in practical trades tend to have a more traditional accent and use more local vocabulary.

These parents therefore seem to agree that accents which are neutral, standard and formal are associated with good manners, better practice, wealth and prestige. While they agree that slang and local and traditional accents should be preserved (for use in appropriate situations or by appropriate people, perhaps), all seem to recognise the concept of a prestige variety, though do not think that it is important for the purposes of communicaiton for us all to speak with the same (standard) accent. And, we think, there is more prestige associated with SSBE, even if it is not the accent of themselves or their children. In mixed accent systems in Scotland, we would therefore expect overt attitudes 
favouring SSBE, even if children are phonologically SSE, and even if the attitudes are not particularly accurate, linguistically.

\section{Conclusion}

These case studies aimed to find out more about the potential for the effects of mixed parental accents of native English input on monolingual English speaking children's own phonological systems, investigated in a Scottish context. First, we observed that SSE can arise even within a mixed accent family (Case Study 2), though detailed phonetic analysis in the style of Hewlett et al. (1999) or Scobbie $(2005,2006)$ would be expected to find very subtle phonetic effects of parental accent disrupting subtle or complex parts of the system. The children with impressionistically mixed accents displayed, in addition to broadly SSE characteristics, SSBE-influenced elements such as diphthongal FACE and GOAT and non-rhoticity, but not in an exceptionless way. We also observed in this case study that siblings in the same family can have markedly different accents, even without the geographical family relocation described by Chambers (1992) for example, that affected older and younger siblings so differently. Thus the question remains open as to how accent mixing moves from idiosyncratic variation in performance to a new, stable, mixed system - and how often.

In Case Study 1, diphthongal (SSBE-influenced) realisations of the FACE and GOAT lexical sets were found, in line with Schützler (2010, in press). In Case Study 2, inter-sibling variation in the influence of SSBE was found both in the realisation of FACE, in contrast between LOT and THOUGHT and in the extent of non-rhoticity. A questionnaire survey revealed an awareness of the potential social constructions based on the use of a standard or prestige accent in a particular geographical area such as Scotland, but little indication was found that a child's phonological system might be influenced towards SSBE by a postive parental attitude to either SSBE specificaly or to the importance of standards generally.

We are fully aware that the case studies above represent an extremely small sample size, but they serve to support the general case for mixed accent study which our literature review makes, and confirms the viability of a couple of specific variables in the Scottish context. They also demonstate clearly that extensive variation can be expected, even within families: children can differ from their parents and siblings from each other. Currently, the precise causes of the variation are unknown, as are the nature of more or less common patterns. Demographic and phonological data alone are unlikely to be sufficient to form a model of such variation: both qualitative data on attitudes and detailed information on a family's social and dialectal context will be required. With phonological data, there might be a tendency to take any evidence of contrast as being unequivocal, whereas it seems that factors such as the degree of dipthongisation or rhoticity will tend to be approached in a more gradient way, but we would suggest gradience is importance for both sorts of evaluation.

In line with Scobbie $(2005,2006)$ we would also want to know about monolingual speakers growing up in areas of Scotland where the dialect they hear from their peers is different from the native English varieties heard at home. This type of approach could address an atypical koineization situation, since it appears from anecdotal observation to be relatively common in Glasgow for the children of SSBE-accented parents living in a middle class context to mix with many SSE speaking peers, while in Edinburgh it appears not uncommon for SSE-accented parents to observe their children mixing with many more SSBE-speaking friends and neighbours (a situation previously 
restricted to boarding schools or other fee-paying schools with a largely SSBE-speaking intake). Thus phonological models may vary in their frequency of use as well as in social meaning, depending on context. This could be expected in turn have a bearing on accent use. A full model would require taking into account sociolinguistic variation in the communities in which the families live, which exposes them to different types of Scottish and English accents, some aspects of which will be socially structured and hence meaningful. In these contexts, it would be interesting to know about parental attitudes on which particular accents might be prestigious, and to whom.

The links between phonology, identity and attitude are clearly important, not just on the ScottishEnglish border (AISEB 2012), but within Scotland itself. We therefore do not think that it would be a useful starting point for the study of the phonological mixing of SSE and SSBE to accept the claim that "Glasgow is different. It cannot be considered a 'border-town' and therefore the link between local identity and language use has potentially different underlying motivations" (Braber and Butterfint 2008, 24). We think it is likely that the communities of standard English speakers that exist within Scotland may create their own, equally porous, accent-based microborders, yet with reference to the selfsame SSE and SSBE and the attitudes speakers have towards them. What differs most clearly between the Central Belt and the Borders are the nature and distribution of local vernacular patterns and of course the abstract presence of a formal border. Yet in the Central Belt, there are still overt and implicit attitudes about the social meaning and the local distribution of Scottish and English accents.

As lifelong long-term residents of the Central Belt of Scotland, we end on a personal note. Our pilot empirical results, highly limited though they are, do reflect our experience. They seem indicative of cases of accent mixture of SSE and SSBE in adults and children: such mixed systems are both common, yet hard to pin down. It would clearly be much easier to restrict our phonological research to well-established standard accents of English, examining only clear cases of SSE, instead of having to deal with a difficult, variable situation. But which is more useful from a theoretical perspective? Our view (as with Schützler in press) is that there is a need to address the gap in the phonological literature, a literature that tends to focus on monolingual and monodialectal / standard accent systems, often overlooking the role of mixed accent input on monolingual language acquisition. The resulting linguistic systems, whethervariable or stable, and the influences that help create them are relevant to general theories of acquisition, phonology, sociolinguistic variation and phonological change rather than being assumed to be merely an an area of idiosyncratic variation that can be conveniently excluded from study.

\section{Acknowledgements}

We would like to thank Professor Jane Stuart-Smith at the Glasgow University Laboratory of Phonetics (GULP), for her advice and encouragement. Thanks are due also to CASL staff particularly Dr. Joanne Cleland for the ULTRAX recordings (EPSRC-funded, EP/I027696/1), and the parents and children who participated. 


\section{References}

AISEB. 2012. Accent and Identity on the Scottish-English Border. URL: http://www.york.ac.uk/res/aiseb/

Aitken, A. J. 1979. "'Scottish Speech:A historical view with special reference to the Standard English of Scotland." In: Languages of Scotland, edited by A. J. Aitken and T. MacArthur, 85-118. Edinburgh: Chambers.

Alam, F., and Stuart-Smith, J. 2011. "Identity and ethnicity in /t/in Glasgow-Pakistani High-School Girls. In Wai-Sum Lee, W-S., \& Zee, E. (eds.). Proceedings of the 17th International Congress of Phonetic Sciences, Hong Kong, China. pp. 216-219.

Beal, J. C. 2010. An Introduction to Regional Englishes: Dialect Variation in England. Great Britain: Edinburgh University Press.

Boersma, P. (2001). PRAAT, a system for doing phonetics by computer. Glot International, 5(9/10), 341-345.

Braber, N., and Butterfint, Z. 2008. "Local identity and sound change in Glasgow - A pilot study." In: Leeds Working Papers 13: 22-33. URL: http://www.leeds.ac.uk/linguistics/WPL/WP2008/2.pdf

Chambers, J. K. 1992. “Dialect Acquisition”. Language 68(4): 673-705.

Chirrey, D. 1999. "Edinburgh: descriptive material." In: Urban Voices: Accent Studies in the British Isles, edited by P. Foulkes and G. Docherty, 223-229. London, UK: Arnold.

Corbett, J. and Stuart-Smith, J. 2012. Standard English in Scotland. In: Standards of English: Codified Standards Around the World, edited by R. Hickey, 72-95. Cambridge, UK: Cambridge University Press.

Corbett, J. and Stuart-Smith, J. 2013. English in Scotland. In: World Englishes: Volume I: The British Isles., edited by T. Hopkins, J. McKenny. and K. Decker, 189-217. London, UK: Continuum,.

Docherty, G.J., Foulkes, P., Dodd, B. and Milroy, L. 2002. "The Emergence of Structured Variation in the Speech of Tyneside Infants". Final report to the United Kingdom Economic and Social Research Council, grant R000237417.

Docherty, G.J., Foulkes, P., Tillotson, J. and Watt, D.J.L. 2006. “On the scope of phonological learning: issues arising from socially-structured variation". In: Laboratory Phonology. Edited by L. Goldstein, D.H. Whalen and C.T. Best, 393-421. Berlin: Mouton de Gruyter.

Giegerich, Heinz J. 1992. English Phonology: An Introduction. Cambridge, UK: Cambridge University Press. 
Gordeeva, O. 2005. "Language Interaction in the Bilingual Acquisition of Sound Structure: a longitudinal study of vowel quality, duration and vocal effort in pre-school children speaking Scottish English and Russian." PhD thesis, Queen Margaret University College. URL: http://etheses.qmu.ac.uk/152/

Hewlett, N., Matthews, B. and Scobbie, J.M. 1999. "Vowel duration in Scottish English speaking children." In: Ohala, J.J., Hasegawa, Y., Ohala, M. Granville, G. and Bailey, A.C. (eds.) Proceedings of the XIVth International Congress of Phonetic Sciences. Volume 3:2157-2160.

Howard, S. 2007. "English Speech Acquisition." In: The International Guide to Speech Acquisition, edited by S. McLeod, 188-203. Clifton Park, NY: Thomson Delmar Learning.

Inoue, F. 1996. "Subjective Dialect Division in Great Britain." American Speech 71(2): 142-161.

Jacewicz, E., Fox, R. A. and Salmons, J. 2011. "Regional Dialect Variation in the Vowel Systems of Typically Developing Children." Journal of Speech, Language and Hearing Research 54(2): 448470.

Johnston, P. 1997. "Regional Variation". In: The Edinburgh History of the Scots Language, edited by C. Jones, 378-432, Edinburgh, UK: Edinburgh University Press.

Johnston, Paul. 2007. "Scottish English and Scots". In: Language in the British Isles, edited by D. Britain, 75-104. Cambridge, UK: Cambridge University Press.

Kerswill, P. 1996. “Children, Adolescents, and Language Change". Language Variation and Change 8: 177-202.

Kerswill, P. 2003. "Dialect levelling and geographical diffusion in British English." In: Social Dialectology: In honour of Peter Trudgill, edited by D. Britain and J. Cheshire, 223-243. Amsterdam/Philadelphia: John Benjamins Publishing Company.

Kerswill, P. and Williams, A. 2000. "Creating a New Town koine: Children and language change in Milton Keynes." Language in Society 29(1): 65-115.

Lawson, E., Scobbie, J.M. and Stuart-Smith, J. 2011. "The social stratification of tongue shape for postvocalic/r/ in Scottish English." Journal of Sociolinguistics 15: 256-268.

Lawson, E., Scobbie, J.M. and Stuart-Smith, J. 2013. "Bunched/r/ promotes vowel merger to schwar: An Ultrasound Tongue Imaging study of Scottish sociophonetic variation". Journal of Phonetics 41(3-4): 198-210.

Macafee, C. 1997. "Ongoing Change in Modern Scots: The social dimension." In: The Edinburgh History of the Scots Language, edited by C. Jones, 514-548. Edinburgh, UK: Edinburgh University Press.

Macaulay, R. K. S. 1975. "Negative prestige, linguistic insecurity, and linguistic self-hatred." Lingua 36(2-3): 147-161. 
MacFarlane, A. E. and Stuart-Smith, J. 2012. "'One of them sounds sort of Glasgow Uni-ish'. Social judgements and fine phonetic variation in Glasgow." Lingua 122(7): 764-778.

Matthews, B. M. 2001. "On variability and the acquisition of vowels in normally developing Scottish children (18-36 months)." PhD thesis, Queen Margaret University College. URL: http://www.qmu.ac.uk/sls/pg/pgtheses.htm

Maver, I. 2000. Glasgow. Edinburgh, UK: Edinburgh University Press.

Preston, D. R. 2002. "Language with an Attitude." In: The Handbook of Language Variation and Change, edited by J. K. Chambers, P. Trudgill, and N. Schilling-Estes, 40-66. Oxford, UK: Blackwell Publishing.

Roach, P. 2004. "British English: Received Pronunciation." Journal of the International Phonetic Association 34(2): 239-245.

Roberts, J. and Labov, W. 1995. "Learning to talk Philadelphian: Acquisition of short $a$ by preschool children." Language Variation and Change 7(1): 101-112.

Schützler, O. 2010. "Unstable Close-Mid Vowels in Modern Scottish English." In: Linguistic Insights, Volume 13: New Trends and Methodologies in Applied English Language Research: Diachronic, Diatopic and Contrastive Studies, edited by Carlos Prado-Alonso, Lidia Gómez-García, Iria Pastor-Gómez \& David Tizón-Couto, 153-182. Bern, Switzerland: Peter Lang AG.

Schützler, O. In press A Sociophonetic Approach to Scottish Standard English. Amsterdam: John Benjamins.

Scobbie, J. M. 2005. "Interspeakervariation among Shetland Islanders as the long term outcome of dialectally varied input: speech production evidence for fine-grained linguistic plasticity." In: QMU Speech Science Research Centre Working Papers, WP-2. URL: http://eresearch.qmu.ac.uk/140/1/no2.pdf

Scobbie, James M. 2006. "Flexibility in the face of incompatible English VOT systems." In: Laboratory Phonology 8 - Varieties of Phonological Competence. Phonology and Phonetics, edited Goldstein, M. L., Whalen, D. H. and Best, C. 367-392. Berlin/New York: Mouton de Gruyter.

Scobbie, J. M., Gordeeva, O. and Matthews, B. 2007. "Scottish English Speech Acquisition." In: The International Guide to Speech Acquisition, edited by S. McLeod, 221-240. Clifton Park, NY: Thomson Delmar Learning. URL [updated version]: http://eresearch.qmu.ac.uk/149/

Scobbie, J. M., Hewlett, N. and Turk, A. E. 1999. "Standard English in Edinburgh and Glasgow: the Scottish Vowel Length Rule revealed." In: Urban Voices: Accent Studies in the British Isles, edited by P. Foulkes and G. Docherty, 230-245. London, UK: Arnold.

Scobbie, J.M., Stuart-Smith, J. and Lawson, E. 2012. "Back to front: a socially-stratified ultrasound tongue imaging study of Scottish English /u/." Rivista di Linguistica / Italian Journal of Linguistics 24(1): 103-148. 
Scottish Government. 2011. Scotland's Census 2011. URL: http://www.scotlandscensus.gov.uk/

Scottish Government. 2012. Scottish Index of Multiple Deprivation. URL: http://www.scotland.gov.uk/Topics/Statistics/SIMD

Smith, J., Durham, M. and Fortune, L. 2007. “'Mam, ma troosers is fa' in doon!' Community, caregiver and child in the acquisition of variation in Scottish dialect." Language Variation and Change 19(1): 63-99.

Starks, D. and Bayard, D. 2002. "Individual Variation in the Acquisition of Postvocalic/r/: Day Care and Sibling Order as Potential Variables." American Speech 77(2): 184-194.

Stuart-Smith, J. 1999. "Glasgow: accent and voice quality." In: Urban Voices: Accent Studies in the British Isles, edited by P. Foulkes and G. Docherty, 203-222. London, UK: Arnold.

Stuart-Smith, J. 2007. "A Sociophonetic Investigation of Postvocalic/r/ in Glaswegian Adolescents." In: Proceedings of the XVIth International Congress of Phonetic Sciences (ICPhS). Saarbrücken, Germany, 6-10 August 2007, edited by Trouvain, J., and Barry, W. J., 1449-1452. Saarbrücken, Germany: Pirrot.

Stuart-Smith, J., Timmins, C. and Tweedie, F. 2007. "Talkin' Jockney'? Variation and change in Glaswegian accent." Journal of Sociolinguistics 11(2): 221-260.

Stuart-Smith, J., Pryce, G., Timmins, C., and Gunter, B. 2013. "Television can also be a factor in language change: evidence from an urban dialect”. Language 89(3): 501-536.

Stuart-Smith, J., Lawson, E., and Scobbie, J.M. 2014. "Derhoticisation in Scottish English: A Sociophonetic Journey." In: Advances in Sociophonetics, edited by C. Celata, S. Calmai and P. Bertinetto, 59-96.: Amsterdam: John Benjamins.

Surek-Clark, C. 2000. "Dialect Acquisition and Prestige". U. Penn Working Papers in Linguistics 6.3: 259-267.

Tagliamonte, S. A. and Molfenter, S. 2007. "How'd you get that accent?: Acquiring a second dialect of the same language." Language in Society 36(5): 649-675.

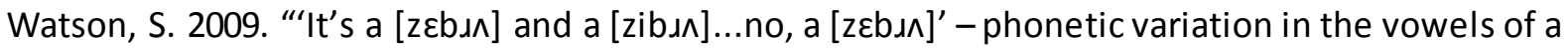
child of 3;1 with parents of differing British English accents." Unpublished MA Dissertation, University of Glasgow.

Wells, J. C. 1982. Accents of English 2 - The British Isles. Cambridge, UK: Cambridge University Press.

Ultrax. 2013. Ultrax: Real Time Tongue Tracking for Speech Therapy. URL: http://www.ultraxspeech.org/team 


\section{Appendix. ULTRAX accent questionnaire (originally formatted and presented on 5 pages)}

\section{Instructions}

Please complete Part A for each child who was recorded for the ULTRAX p roject. You only need to complete Part B once, since it is more about your views. Please highlight/delete answers as appropriate. Please give details for any or all questions that you wish to answer, and ignore ones that you don't want to answer. Even partial information will be useful to us.

\section{Part A: Child and Family}

Date of completion (i.e. today's date). Child's age today in years and months. What school was your child going to at the time of the recording?

Specifically, we'd like to know the postcode(s) of the main home(s) of the child between the ages of 1 and 6 years, with approximate ages in each location.

More generally, where did your child stay, from birth until the present time? We want to know this information to help judge if these locations have affected your child's accent.

Would you categorise your child's (current) accent as one of the following? Please tick one box. (a) Scottish, (b) Irish, (c) Northern English, (d) Southern English, (e) Welsh, (f) a mixture, (g) other.

If you have answered (f) or (g), or feel that the categories above do not cover your child's accent, please give us more details. For example, is your child's accent characteristic of a particular country, city or region? If so, where? What is the mixture?

How would you categorise the accents of the adults who have looked after and brought up your child at home in the role of parent or guardian? Please indicate the appropriate accent for each. We don't mean teachers, baby-sitters or occasional child-minders, but if you think a nanny or long-term child-minder has had a significant influence on your child's accent, please indicate this too.

Adult\#1 (this is you) has what role (e.g. mother)? (a) Scottish, (b) Irish, (c) Northern English, (d) Southern English, (e) Welsh, (f) a mixture, (g) other. <Repeat for Adult\#2. Repeat for Adult\#3.> If you have answered ( $\mathrm{f}$ ) or ( $\mathrm{g}$ ), or feel that the categories above do not cover the adult's accent, please give us more details. For example, is the care-giver's accent characteristic of a particular country, city or region? If so, where? Have you any other comments to make?

\section{Part B: Community and location}

What is the normal accent of the place where you stay, in the community nearyou?

Do you think you can recognise the accent of your local area? If so, how? What is it like?

Does the local accent vary a bit? What are the varieties?

Where do you think people start sounding different from your local area? What are the accents nearby that are different to your local area? 
$<$ UK Map > Please draw lines onto the map, to indicate where you feel regional accents are located. Please feel free to add any additional information or labels onto or around the map if you wish to do so.

Any additional information that you think is relevant, and your opinions (positive and negative) on any particular accents of the UK, your own accent, or your child's accent would be welcome. For example, you might have a view on some of the following questions, or others.

1. Do you think children speak with too much slang?

2. Do old people have more varied accents than young ones?

3. Is it important to preserve local accents and old-fashioned words?

4. Is it important that we all speak with a standard accent to make communication easy?

5. Can you understand foreign-accented speakers of English easily?

6. Is American English easy to understand? 